\section{Spätzünder mit Herzblut}

_ Aus technischer Sicht bin ich ein Spätzünder. Mein erstes Handy beispielsweise hat mir mein Bruder zum 20. Geburtstag geschenkt. Ich hielt das für unnötig. Doch seiner Ansicht nach war es zu diesem Zeitpunkt indiskutabel, nicht mehr immer und überall erreichbar zu sein. Also gut, ich lernte meinen neuen Begleiter schätzen und lieben.

_ Damit ist meine Affinität für neue Medien ins Rollen gekommen. Gut, sagen wir ins Trudeln. Denn bis zur nächsten Stufe - Computer mit Internetzugang gingen noch ein paar Jahre ins Land. Und während ich mir den Saft noch mühsam aus einem analogen Modem gezogen habe, konnten sich andere ein Leben ohne W-LAN schon gar nicht mehr vorstellen. Heute weiß ich auch, dass es viel angenehmer ist, nicht ständig das Modemkabel entwirren zu müssen und weiter als 1,5 m Kabellänge von der Telefonbuchse entfernt surfen zu können. Ich muss die Vorteile immer erst am eigenen Leib erfahren und finde dann zugegebenermaßen großen Gefallen daran.

_ Kürzlich habe ich es auf die Spitze getrieben: Ich habe mir ein FacebookProfil eingerichtet. Sie wissen das sicherlich schon seit Jahren, aber es macht wirklich großen Spaß. Und zwar so viel, dass ich Ihnen gleich meine neue Lieblingsseite empfehlen möchte: Sie heißt „Thieme liebt Ergotherapeuten“. Unter www.facebook.com/thiemeliebtergotherapeuten erwartet Sie Interessantes, Aktuelles, Unterhaltsames und vor allem Ergotherapeutisches gespickt mit einer Extraportion Herzblut!

_ Bei meinem Bruder beobachte ich übrigens mittlerweile einen technischen Rückschritt. Sein Handy ist entweder ausgeschaltet oder unauffindbar. Ich habe neulich eine geschlagene Woche gebraucht, bis ich ihm (dann nachträglich) zum Geburtstag gratulieren konnte. Eine eigene E-Mail-Adresse, geschweige denn ein Facebook-Profil besitzt er natürlich nicht. Vielleicht muss ich da jetzt mal als kleine Schwester ran ...

Ihre

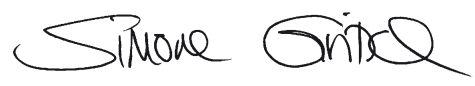

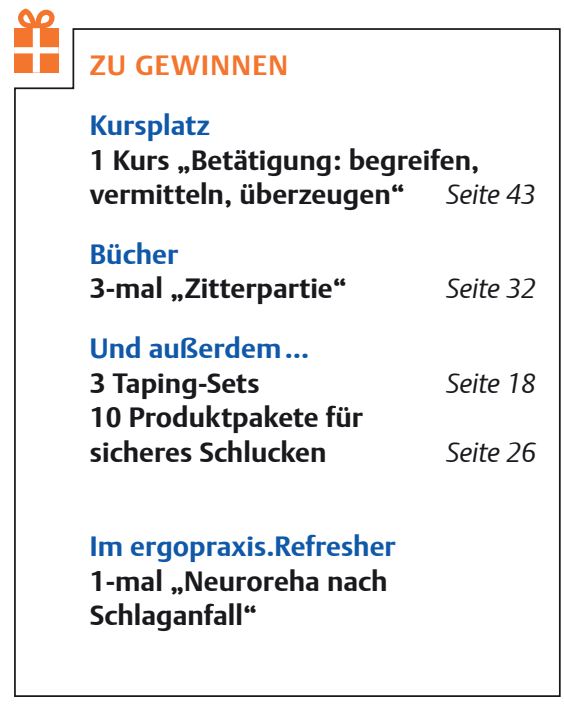

Besuchen Sie uns auf Facebook unter www.facebook.com/thiemeliebtergotherapeuten!

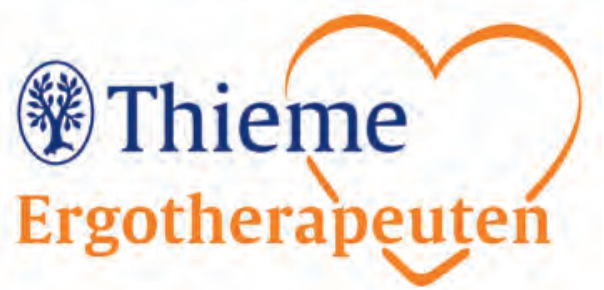

